$\underline{\text { Research fraud }}$

\section{New ways of shading truth}

Los Angeles

PRESSURE to publish and a lingering "premed syndrome" among medical researchers contribute not only to the relatively rare cases of outright scientific fakery, but also to various much more frequent abuses of scientific publication, according to medical researchers and journal editors speaking at the annual meeting of the American Association for the Advancement of Science.

Dr Edward Huth, editor of Annals of Internal Medicine, said that journals and scientific societies should consider adopting a precise definition of authorship to prevent one of the most frequent abuses, "false authorship". Other common abuses that he had encountered were the practice of slicing one study into a series - "salami science" - and repetitive publication.

Huth said false authorship usually occurs when a department chairman, laboratory technician or anyone not directly responsible for the intellectual content of the paper is listed as an author. Huth told of a case in which a researcher learned only by accident that his name had been included among the authors of a paper submitted to the Annals. While the researcher had provided some technical advice to the main author, at another institution, he had contributed neither to the design of the experiment nor to its execution, and had not even seen the final paper or any drafts. In fact, he had specifically declined an offer to be listed as an author.

Another common deception is statistical manipulation of data. Dr John Bailar, a statistical consultant to the New England Journal of Medicine, said that the deliberate misuse of statistics should be part of an "expanded definition of fraud". Inappropriate statistical tests have often been used to exaggerate the significance of the results presented. In some cases, authors seem to have tried several statistical tests, reporting only that which gives the best results. Hypotheses suggested by the data are often reported with $P$-values, which have meaning only for hypotheses formulated independently of data.

Huth suggested several steps that could be taken to curtail these abuses, which, he said, because of their "frequency and ubiquity", make them "more worth our attention than fakery". Although little can be done to prevent "salami science", repetitive publication could be checked by specifically asking reviewers to bring prior publications of the same material to the attention of editors.

False authorship may be more difficult to eliminate. The Annals requires each author to sign a form acknowledging that he has seen the final version of the paper and agrees to its publication. The shortcomings of even this approach were revealed by the case Huth mentioned above: the eight signatures on the forms bore a striking similarity.

Dr Robert Petersdorf, dean of medicine and vice-chancellor for health sciences at the University of California at San Diego, suggested that the problem lies deeper. Science has become "too big, too competitive, too entrepreneurial, too bent on "winning',". Federal research grants to medical schools have grown from $\$ 436$ million in 1960 to $\$ 2,351$ million in 1981 , increasing proportionately much faster than enrolment.

Petersdorf said that the "pre-med syndrome" of intense competition and resorts to cheating carries through to competition for grants and for tenure, "eroding the moral fibre" of physicians.

The deputy editor of the New England Journal of Medicine, Dr Marcia Angell, suggested that grant-making agencies and

\section{Arianespace}

\section{Sky-high insurance unfair}

ARIANESPACE, the largely French company that now runs Europe's Ariane space launcher on something approaching a commercial basis, is fed up with the huge insurance premiums that are being asked of satellite makers for launch on Ariane. According to M. Frédéric d'Allest, president of Arianespace, his company is being forced to pay for the losses made by insurers of the ill-fated Palapa B-2 and Westar-6 satellites, mis-launched from and then recovered the US space shuttle, and for recent failure of Syncom IV-3 and the earlier TDRS-A, also both shuttle-launched. Insurance premiums are now so high, 20 per cent of the capital cost of Arabsat, recently launched by Ariane, for example, that the growth of the satellite communications business itself is under threat.

According to Arianespace officials, before the shuttle setbacks premiums were set at around 6 per cent for a shuttle launch and 9-11 cent for Ariane. This was after Ariane had suffered two early failures, and reflected a feeling among the insurers that because the shuttle was manned, there should be less risk of uncorrectable trouble with a shuttle launch. But this did not take into account the large, multi-million dollar booster rockets needed by shuttlelaunched satellites to take them from the low orbit of the shuttle up to geostationary heights, says Arianespace. This is the technology in which the shuttle has faced difficulties, while Ariane, which launches into an elliptical "geostationary transfer" orbit from which only a small "apogee motor' is needed to reach geostationary orbit, has gone from strength to strength. Ariane has now successfully launched 13 commercial satellites in its last eight flights, and it is time the insurers recognized the cards. tenure committees could help eliminate these abuses at source by refusing to consider more than the three articles a candidate considers to be his best in a given year.

Whether pressures to publish are responsible for the more serious cases of fraud remains unknown. Patricia Woolf, at the sociology department at Princeton University, noted that the number of papers published per scientist per year has changed little but in one group she has studied in detail (chemists), the number of "super-productive" researchers has clearly grown.

The National Institutes of Health (NIH), which investigates cases of fraud involving federal research grants, say that they receive about two reports a month of fraud or scientific misconduct, a minute fraction out of the 20,000 research projects active on any given day. Dr William Raub, deputy director for extramural research and training, said that NIH will nonetheless issue rules this summer requiring institutions that receive federal funds to report any cases of suspected fraud.

Stephen Budiansky

But the insurance companies are reckoned to have lost almost $\$ 200$ million on Palapa and Westar alone, despite their recovery, and another $\$ 85$ million for Syncom, and they are fighting shy. Premiums are now around 18 per cent, with higher figures for those the companies think can pay, such as the Arabs. The premiums are the same for the shuttle and for Ariane, claims Arianespace, and they come as a package, making no distinction between the launch to first orbit (which the shuttle has accomplished perfectly) and the boost phase. M. Deschamps, director-general of Arianespace, would like the insurers to make a distinction by charging the same to Ariane and the shuttle for the first injection, and then more to shuttle customers for the boost, thus reflecting the apparently higher risk. At present the terms are "a brake" on growth, says Deschamps.

And Arianespace is certainly looking for growth, with 25 future satellites in the queue, an order book totalling FF 6,500 million ( $£ 600$ million), a second launch pad at the launch site in Kourou, French Guiana, nearing completion and a third planned, apart from French space agency work on advanced and more powerful forms of Ariane, including a mini-shuttle, Hermes. And while President Reagan is attempting to shift more of the real costs of shuttle launches onto the customers, raising launch fees, Arianespace is planning to follow suit to raise profits, but not so much as to threaten the 30 per cent of the world market for satellite launchers the company hopes to be taking from 1987 on. Here is one field in which Europe feels at last that, for the time, it is holding one or two trump

Robert Walgate 